\title{
A New Hybrid Algorithm for a System of Generalized Mixed Equilibrium Problems and Fixed Point of Quasi- $\boldsymbol{\phi}$-Asymptotically Nonexpansive Mappings
}

\author{
Jinhua Zhu and Shih-Sen Chang \\ Department of Mathematics, Yibin University, Yibin, Sichuan 644007, China \\ Correspondence should be addressed to Shih-Sen Chang, changss@yahoo.cn
}

Received 6 March 2011; Accepted 11 April 2011

Academic Editors: S. Deng and K. A. Lurie

Copyright (C) 2011 J. Zhu and S.-S. Chang. This is an open access article distributed under the Creative Commons Attribution License, which permits unrestricted use, distribution, and reproduction in any medium, provided the original work is properly cited.

The purpose of this paper is to use a new hybrid algorithm for finding a common element of the set of solutions for a system of generalized mixed equilibrium problems and the set of common fixed points for an infinite family of quasi- $\phi$-asymptotically nonexpansive mappings. Under suitable conditions some strong convergence theorems are established in a uniformly smooth and strictly convex Banach space with Kadec-Klee property. The results presented in the paper improve and extend some recent results.

\section{Introduction}

Throughout this paper, we denote by $\mathbb{N}$ and $\mathbb{R}$ the sets of positive integers and real numbers, respectively. We also assume that $E$ is a real Banach space, $E^{*}$ is the dual space of $E, C$ is a nonempty closed convex subset of $E$, and $\langle\cdot, \cdot\rangle$ is the pairing between $E$ and $E^{*}$. In the sequel, we denote the strong convergence and weak convergence of a sequence $\left\{x_{n}\right\}$ by $x_{n} \rightarrow x$ and $x_{n} \rightarrow x$, respectively.

Let $\psi: C \rightarrow \mathbb{R}$ be a real-valued function, $A: C \rightarrow E^{*}$ a nonlinear mapping, and $\left\{\Theta_{i}: C \times C \rightarrow \mathbb{R}, i=1,2, \ldots, N\right\}$ a finite family of equilibrium bifunctions, that is, $\Theta_{i}(u, u)=0$ for each $u \in C$. The "so-called" system of generalized mixed equilibrium problems (SGMEP) for functions $\left(\Theta_{1}, \Theta_{2}, \ldots, \Theta_{N}, A, \psi\right)$ is to find a common element $x^{*} \in C$ such that

$$
\begin{array}{cc}
\Theta_{1}\left(x^{*}, y\right)+\left\langle A x^{*}, y-x^{*}\right\rangle+\psi(y)-\psi\left(x^{*}\right) \geq 0, & \forall y \in C, \\
\Theta_{2}\left(x^{*}, y\right)+\left\langle A x^{*}, y-x^{*}\right\rangle+\psi(y)-\psi\left(x^{*}\right) \geq 0, & \forall y \in C, \\
\vdots & \\
\Theta_{N}\left(x^{*}, y\right)+\left\langle A x^{*}, y-x^{*}\right\rangle+\psi(y)-\psi\left(x^{*}\right) \geq 0, & \forall y \in C .
\end{array}
$$


We denote the set of solutions of (1.1) by $\Omega:=\bigcap_{i=1}^{N} \Omega\left(\Theta_{i}, \psi\right)$, where $\Omega\left(\Theta_{i}, \psi\right)$ is the set of solutions to the generalized mixed equilibrium problem:

$$
\Theta_{i}\left(x^{*}, y\right)+\left\langle A x^{*}, y-x^{*}\right\rangle+\psi(y)-\psi\left(x^{*}\right) \geq 0, \quad \forall y \in C .
$$

Special examples are as follows.

(i) If $A=0$ and $N=1$, the problem (1.1) is equivalent to finding $x^{*} \in C$ such that

$$
\Theta\left(x^{*}, y\right)+\psi(y)-\psi\left(x^{*}\right) \geq 0, \quad \forall y \in C,
$$

which is called the mixed equilibrium problem (MEP) [1]. The set of solutions to (1.3) is denoted by MEP.

(ii) If $\Theta=0$ and $N=1$, the problem (1.1) is equivalent to finding $x^{*} \in C$ such that

$$
\left\langle A x^{*}, y-x^{*}\right\rangle+\psi(y)-\psi\left(x^{*}\right) \geq 0, \quad \forall y \in C,
$$

which is called the mixed variational inequality of Browder type (VI) [2]. The set of solutions to (1.4) is denoted by $\mathrm{VI}(C, A, \psi)$.

Recently, many authors studied the problems of finding a common element of the set of fixed point for a nonexpansive mapping and the set of solutions for an equilibrium problem in the setting of Hilbert space and uniformly smooth and uniformly convex Banach space, respectively (see, e.g., [3-5] and the references therein).

Motivated and inspired by the researches going on in this direction, the purpose of this paper is using a hybrid algorithm for finding a common element of the set of solutions for a system of generalized mixed equilibrium problems and the set of common fixed points for an infinite family of quasi- $\phi$-asymptotically nonexpansive mappings. Under suitable conditions some strong convergence theorems are established in a uniformly smooth and strictly convex Banach space with Kadec-Klee property. The results improve and extend the corresponding results in [6-12].

\section{Preliminaries}

First, we recall some definitions and conclusions.

The mapping $J: E \rightarrow 2^{E^{*}}$ defined by

$$
J(x)=\left\{x^{*} \in E^{*}:\left\langle x, x^{*}\right\rangle=\|x\|=\left\|x^{*}\right\|\right\}, \quad x \in E,
$$

is called the normalized duality mapping. By the Hahn-Banach theorem, $J(x) \neq \emptyset$ for each $x \in E$.

A Banach space $E$ is said to be strictly convex if $\|x+y\| / 2<1$ for all $x, y \in U=\{z \in E$ : $\|z\|=1\}$ with $x \neq y$. $E$ is said to be uniformly convex if, for each $\epsilon \in(0,2]$, there exists $\delta>0$ such that $\|x+y\| / 2<1-\delta$ for all $x, y \in U$ with $\|x-y\| \geq \epsilon$. E is said to be smooth if the limit

$$
\lim _{t \rightarrow 0} \frac{\|x+t y\|-\|x\|}{t}
$$


exists for all $x, y \in U$. $E$ is said to be uniformly smooth if the above limit exists uniformly in $x, y \in U$.

Remark 2.1. The following basic properties can be found in Cioranescu [13].

(i) If $E$ is a uniformly smooth Banach space, then $J$ is uniformly continuous on each bounded subset of $E$.

(ii) If $E$ is a reflexive and strictly convex Banach space, then $J^{-1}$ is norm-weak continuous.

(iii) If $E$ is a smooth, strictly convex, and reflexive Banach space, then $J$ is single-valued, one-to-one, and onto.

(iv) A Banach space $E$ is uniformly smooth if and only if $E^{*}$ is uniformly convex.

(v) Each uniformly convex Banach space $E$ has the Kadec-Klee property, that is, for any sequence $\left\{x_{n}\right\} \subset E$, if $x_{n} \rightarrow x \in E$ and $\left\|x_{n}\right\| \rightarrow\|x\|$, then $x_{n} \rightarrow x$.

Next we assume that $E$ is a smooth, strictly convex, and reflexive Banach space and $C$ is a nonempty closed convex subset of $E$. In the sequel, we always use $\phi: E \times E \rightarrow \mathbb{R}^{+}$to denote the Lyapunov functional defined by

$$
\phi(x, y)=\|x\|^{2}-2\langle x, J y\rangle+\|y\|^{2}, \quad \forall x, y \in E .
$$

It is obvious from the definition of $\phi$ that

$$
(\|x\|-\|y\|)^{2} \leq \phi(x, y) \leq(\|x\|+\|y\|)^{2}, \quad \forall x, y \in E .
$$

Following Alber [14], the generalized projection $\Pi_{C}: E \rightarrow C$ is defined by

$$
\Pi_{C}(x)=\arg \inf _{y \in C} \phi(y, x), \quad \forall x \in E .
$$

Lemma 2.2 (see [14, 15]). Let $E$ be a smooth, strictly convex, and reflexive Banach space and $C$ a nonempty closed convex subset of $E$. Then the following conclusions hold:

(a) $\phi\left(x, \Pi_{C} y\right)+\phi\left(\Pi_{C} y, y\right) \leq \phi(x, y)$, for all $x \in C$ and $y \in E$;

(b) if $x \in E$ and $z \in C$, then

$$
z=\Pi_{C} x \Longleftrightarrow\langle z-y, J x-J z\rangle \geq 0, \quad \forall y \in C ;
$$

(c) for $x, y \in E, \phi(x, y)=0$ if and only $x=y$.

Remark 2.3. If $E$ is a real Hilbert space $H$, then $\phi(x, y)=\|x-y\|^{2}$ and $\Pi_{C}$ is the metric projection $P_{C}$ of $H$ onto $C$.

Let $E$ be a smooth, strictly convex, and reflexive Banach space, $C$ a nonempty closed convex subset of $E, T: C \rightarrow C$ a mapping, and $F(T)$ the set of fixed points of $T$. A point $p \in C$ is said to be an asymptotic fixed point of $T$ if there exists a sequence $\left\{x_{n}\right\} \subset C$ such that $x_{n} \rightarrow p$ and $\left\|x_{n}-T x_{n}\right\| \rightarrow 0$. We denoted the set of all asymptotic fixed points of $T$ by $\tilde{F}(T)$. 
Definition 2.4 (see [16]). (1) A mapping $T: C \rightarrow C$ is said to be relatively nonexpansive if $F(T) \neq \emptyset, F(T)=\tilde{F}(T)$, and

$$
\phi(p, T x) \leq \phi(p, x), \quad \forall x \in C, p \in F(T)
$$

(2) A mapping $T: C \rightarrow C$ is said to be closed if, for any sequence $\left\{x_{n}\right\} \subset C$ with $x_{n} \rightarrow$ $x$ and $T x_{n} \rightarrow y$, then $T x=y$.

Definition 2.5 (see [9]). (1) A mapping $T: C \rightarrow C$ is said to be quasi- $\phi$-nonexpansive if $F(T) \neq \emptyset$ and

$$
\phi(p, T x) \leq \phi(p, x), \quad \forall x \in C, p \in F(T)
$$

(2) A mapping $T: C \rightarrow C$ is said to be quasi- $\phi$-asymptotically nonexpansive if $F(T) \neq \emptyset$ and there exists a real sequence $\left\{k_{n}\right\} \subset[1, \infty)$ with $k_{n} \rightarrow 1$ such that

$$
\phi\left(p, T^{n} x\right) \leq k_{n} \phi(p, x), \quad \forall n \geq 1, x \in C, p \in F(T) .
$$

(3) A mapping $T: C \rightarrow C$ is said to be uniformly $L$-Lipschitz continuous if there exists a constant $L>0$ such that

$$
\left\|T^{n} x-T^{n} y\right\| \leq L\|x-y\|, \quad \forall x, y \in C, \forall n \geq 1
$$

Remark 2.6. (1) From the definition, it is easy to know that each relatively nonexpansive mapping is closed.

(2) The class of quasi- $\phi$-asymptotically nonexpansive mappings contains properly the class of quasi- $\phi$-nonexpansive mappings as a subclass, and the class of quasi- $\phi$-nonexpansive mappings contains properly the class of relatively nonexpansive mappings as a subclass, but the converse may be not true.

Lemma 2.7 (see [6]). Let E be a uniformly convex Banach space, $r>0$ a positive number, and $B_{r}(0)$ a closed ball of $E$. Then, for any given sequence $\left\{x_{i}\right\}_{i=1}^{\infty} \subset B_{r}(0)$ and for any given sequence $\left\{\lambda_{i}\right\}_{i=1}^{\infty}$ of positive numbers with $\sum_{i=1}^{\infty} \lambda_{i}=1$, then there exists a continuous, strictly increasing, and convex function $g:[0,2 r) \rightarrow[0, \infty)$ with $g(0)=0$ such that for any positive integers $i, j$ with $i<j$,

$$
\left\|\sum_{n=1}^{\infty} \lambda_{n} x_{n}\right\|^{2} \leq \sum_{n=1}^{\infty} \lambda_{n}\left\|x_{n}\right\|^{2}-\lambda_{i} \lambda_{j} g\left(\left\|x_{i}-x_{j}\right\|\right) .
$$

Lemma 2.8 (see [6]). Let E be a real uniformly smooth and strictly convex Banach space with KadecKlee property and $C$ a nonempty closed convex subset of $E$. Let $T: C \rightarrow C$ be a closed and quasi$\phi$-asymptotically nonexpansive mapping with a sequence $\left\{k_{n}\right\} \subset[1, \infty), k_{n} \rightarrow 1$. Then $F(T)$ is a closed convex subset of $C$.

For solving the system of generalized mixed equilibrium problems (1.1), let us assume that the function $\psi: C \rightarrow \mathbb{R}$ is convex and lower semicontinuous, the nonlinear mapping 
$A: C \rightarrow E^{*}$ is continuous and monotone, and the bifunction $\Theta_{i}: C \times C \rightarrow \mathbb{R}, i=1,2, \ldots, N$ satisfies the following conditions:

$\left(A_{1}\right) \Theta_{i}(x, x)=0$, for all $x \in C$;

$\left(A_{2}\right) \Theta_{i}$ is monotone, that is, $\Theta_{i}(x, y)+\Theta_{i}(y, x) \leq 0$, for all $x, y \in C$;

$\left(A_{3}\right) \lim \sup _{t \downarrow 0} \Theta_{i}(x+t(z-x), y) \leq \Theta_{i}(x, y)$ for all $x, z, y \in C$;

$\left(A_{4}\right)$ the function $y \mapsto \Theta_{i}(x, y)$ is convex and lower semicontinuous.

Lemma 2.9. Let $E$ be a smooth, strictly convex, and reflexive Banach space and $C$ a nonempty closed convex subset of $E$. Let $\Theta: C \times C \rightarrow \mathbb{R}$ be a bifunction satisfying conditions $\left(A_{1}\right)-\left(A_{4}\right)$. Let $r>0$ and $x \in E$. Then, the following hold.

(i) (Blum and Oettli [17]) There exists $z \in C$ such that

$$
\Theta(z, y)+\frac{1}{r}\langle y-z, J z-J x\rangle \geq 0, \quad \forall y \in C
$$

(ii) (Takahashi and Zembayashi [3]) Define a mapping $T_{r}: E \rightarrow C$ by

$$
T_{r}(x)=\left\{z \in C: \Theta(z, y)+\frac{1}{r}\langle y-z, J z-J x\rangle \geq 0, \forall y \in C\right\}, \quad x \in E .
$$

Then, the following conclusions hold:

(a) $T_{r}$ is single valued;

(b) $T_{r}$ is firmly nonexpansive-type mapping, that is, for all $z, y \in E$,

$$
\left\langle T_{r} z-T_{r} y, J T_{r} z-J T_{r} y\right\rangle \leq\left\langle T_{r} z-T_{r} y, J z-J y\right\rangle
$$

(c) $F\left(T_{r}\right)=\operatorname{EP}(\Theta)=\tilde{F}\left(T_{r}\right)$;

(d) $\mathrm{EP}(\Theta)$ is closed and convex;

(e) $\phi\left(q, T_{r} x\right)+\phi\left(T_{r} x, x\right) \leq \phi(q, x)$, for all $q \in F\left(T_{r}\right)$.

Lemma 2.10 (see [7]). Let $E$ be a smooth, strictly convex, and reflexive Banach space and $C$ a nonempty closed convex subset of $E$. Let $A: C \rightarrow E^{*}$ be a continuous and monotone mapping, $\psi: C \rightarrow \mathbb{R}$ a lower semicontinuous and convex function, and $\Theta: C \times C \rightarrow \mathbb{R}$ a bifunction satisfying the conditions $\left(A_{1}\right)-\left(A_{4}\right)$. Let $r>0$ be any given number and $x \in E$ be any given point. Then, the following hold.

(i) There exists $u \in C$ such that

$$
\Theta(u, y)+\langle A u, y-u\rangle+\psi(y)-\psi(u)+\frac{1}{r}\langle y-u, J u-J x\rangle \geq 0, \quad \forall y \in C .
$$


(ii) If we define a mapping $K_{r}^{\Theta}: C \rightarrow C$ by

$$
\begin{aligned}
K_{r}^{\Theta}(x)=\{ & u \in C: \Theta(u, y)+\langle A u, y-u\rangle \\
& \left.+\psi(y)-\psi(u)+\frac{1}{r}\langle y-u, J u-J x\rangle \geq 0, \forall y \in C\right\}, \quad \forall x \in C .
\end{aligned}
$$

then, the mapping $K_{r}^{\Theta}$ has the following properties:

(a) $K_{r}^{\Theta}$ is single valued;

(b) $K_{r}^{\Theta}$ is a firmly nonexpansive-type mapping, that is,

$$
\left\langle K_{r}^{\Theta} z-K_{r}^{\Theta} y, J K_{r}^{\Theta} z-J K_{r}^{\Theta} y\right\rangle \leq\left\langle K_{r}^{\Theta} z-K_{r}^{\Theta} y, J z-J y\right\rangle, \quad \forall z, y \in E ;
$$

(c) $F\left(K_{r}^{\Theta}\right)=\Omega(\Theta, \psi)=\tilde{F}\left(K_{r}^{\Theta}\right)$;

(d) $\Omega(\Theta, \psi)$ is closed and convex;

(e)

$$
\phi\left(q, K_{r}^{\Theta} x\right)+\phi\left(K_{r}^{\Theta} x, x\right) \leq \phi(q, x), \quad \forall q \in F\left(K_{r}^{\Theta}\right) .
$$

Remark 2.11. It follows from Lemma 2.9 that the mapping $K_{r}^{\Theta}$ is a relatively nonexpansive mapping. Thus, it is quasi- $\phi$-asymptotically nonexpansive.

\section{Main Results}

In this section, we will use the hybrid method to prove some strong convergence theorems for finding a common element of the set of solutions for a system of the generalized mixed equilibrium problems (1.1) and the set of common fixed points for an infinite family of quasi$\phi$-asymptotically nonexpansive mappings in Banach spaces.

Theorem 3.1. Let $E$ be a uniformly smooth and strictly convex Banach space with Kleac-Klee property and $C$ a nonempty closed convex subset of $E$. Let $A: C \rightarrow E^{*}$ be a continuous and monotone mapping, $\psi: C \rightarrow \mathbb{R}$ a lower semicontinuous and convex function, and $\left\{\Theta_{i}\right.$ : $C \times C \rightarrow \mathbb{R}, i=1,2, \ldots, N\}$ be a finite family of bifunction satisfying conditions $\left(A_{1}\right)-\left(A_{4}\right)$. Let $\left\{S_{i}\right\}_{i=1}^{\infty}: C \rightarrow C$ an infinite family of closed and uniformly quasi- $\phi$-asymptotically nonexpansive mappings with a sequence $\left\{k_{n}\right\} \subset[1, \infty)$ and $k_{n} \rightarrow 1$. Suppose that for each $i \geq 1, S_{i}$ is uniformly $L_{i}$-Lipschitz continuous and that $G:=\bigcap_{i=1}^{\infty} F\left(S_{i}\right) \cap \Omega$ is a nonempty and bounded subset in $C$, where 
$\Omega=\bigcap_{i=1}^{N} \Omega\left(\Theta_{i}, \psi\right)$. Let $\left\{x_{n}\right\},\left\{y_{n}\right\},\left\{z_{n}\right\}$, and $\left\{u_{n}^{(k)}\right\}, k=1,2, \ldots, N$, be the sequences generated by

$$
\begin{gathered}
x_{0} \in C, \quad C_{0}=C, \\
z_{n}=J^{-1}\left(\alpha_{n, 0} J x_{n}+\sum_{i=1}^{\infty} \alpha_{n, i} J S_{i}^{n} x_{n}\right), \\
y_{n}=J^{-1}\left(\alpha_{n} J z_{n}+\left(1-\alpha_{n}\right) J x_{n}\right), \\
u_{n}^{(N)} \in C \text { such that, } \forall y \in C, \\
\Theta_{N}\left(u_{n}^{(N)}, y\right)+\left\langle A u_{n}^{(N)}, y-u_{n}^{(N)}\right\rangle+\psi(y)-\psi\left(u_{n}^{(N)}\right) \\
+\frac{1}{r_{n}}\left\langle y-u_{n}^{(N)}, J u_{n}^{(N)}-J u_{n}^{(N-1)}\right\rangle \geq 0, \\
\Theta_{N-1}\left(u_{n}^{(N-1)}, y\right)+\left\langle A u_{n}^{(N-1)}, y-u_{n}^{(N-1)}\right\rangle+\psi(y)-\psi\left(u_{n}^{(N-1)}\right) \\
+\frac{1}{r_{n}}\left\langle y-u_{n}^{(N-1)}, J u_{n}^{(N-1)}-J u_{n}^{(N-2)}\right\rangle \geq 0, \\
\vdots \\
\Theta_{1}\left(u_{n}^{(1)}, y\right)+\left\langle A u_{n}^{(1)}, y-u_{n}^{(1)}\right\rangle+\psi(y)-\psi\left(u_{n}^{(1)}\right)+\frac{1}{r_{n}}\left\langle y-u_{n}^{(1)}, J u_{n}^{(1)}-J y_{n}\right\rangle \geq 0, \\
C_{n+1}=\left\{v \in C_{n}: \phi\left(v, u_{n}^{(N)}\right) \leq \phi\left(v, x_{n}\right)+\xi_{n}\right\}, \quad \forall n \geq 0, \\
x_{n+1}=\Pi C_{n+1} x_{0},
\end{gathered}
$$

where

$$
\begin{aligned}
u_{n}^{(1)} & =K_{r_{n}}^{\Theta_{1}} y_{n}, \\
u_{n}^{(i)} & =K_{r_{n}}^{\Theta_{i}} u_{n}^{(i-1)}=K_{r_{n}}^{\Theta_{i}} K_{r_{n}}^{\Theta_{i-1}} u_{n}^{(i-2)}=K_{r_{n}}^{\Theta_{i}} \cdots K_{r_{n}}^{\Theta_{2}} u_{n}^{(1)} \\
& =K_{r_{n}}^{\Theta_{i}} \cdots K_{r_{n}}^{\Theta_{2}} K_{r_{n}}^{\Theta_{1}} y_{n}, \quad i=1,2, \ldots, N
\end{aligned}
$$

and $K_{r_{n}}^{\Theta_{i}}: C \rightarrow C, i=1,2, \ldots, N$ is the mapping defined by (2.16), $r_{n} \in[d, \infty)$ for some $d>0$, $\xi_{n}=\sup _{u \in G}\left(k_{n}-1\right) \phi\left(u, x_{n}\right), \Pi_{C_{n+1}}$ is the generalized projection of $E$ onto the set $C_{n+1}$, and for each $n \geq 0,\left\{\alpha_{n, i}\right\},\left\{\alpha_{n}\right\}$ are sequences in $[0,1]$ satisfying the following conditions:

(a) $\sum_{i=0}^{\infty} \alpha_{n, i}=1$ for all $n \geq 0$;

(b) $\liminf _{n \rightarrow \infty} \alpha_{n, 0} \cdot \alpha_{n, i}>0$ for all $i \geq 1$;

(c) $0<\alpha \leq \alpha_{n}<1$ for some $\alpha \in(0,1)$.

Then $\left\{x_{n}\right\}$ converges strongly to $\Pi_{G} x_{0}$, where $\Pi_{G}$ is the generalized projection from E onto $G$. 
Proof. We divide the proof of Theorem 3.1 into five steps.

(I) We first prove that $G$ and $C_{n}$ both are closed and convex subset of $C$ for all $n \geq 0$.

In fact, it follows from Lemmas 2.8 and 2.10 that $F\left(S_{i}\right), i \geq 1$, and $\Omega$ both are closed and convex. Therefore $G$ is a closed and convex subset in $C$. Furthermore, it is obvious that $C_{0}=C$ is closed and convex. Suppose that $C_{n}$ is closed and convex for some $n \geq 1$. Since the inequality $\phi\left(v, u_{n}^{(N)}\right) \leq \phi\left(v, x_{n}\right)+\xi_{n}$ is equivalent to

$$
2\left\langle v, J x_{n}-J u_{n}^{(N)}\right\rangle \leq\left\|x_{n}\right\|^{2}-\left\|u_{n}^{(N)}\right\|^{2}+\xi_{n}
$$

therefore, we have

$$
C_{n+1}=\left\{v \in C_{n}: 2\left\langle v, J x_{n}-J u_{n}^{(N)}\right\rangle \leq\left\|x_{n}\right\|^{2}-\left\|u_{n}^{(N)}\right\|^{2}+\xi_{n}\right\} .
$$

This implies that $C_{n+1}$ is closed and convex. The desired conclusions are proved. These in turn show that $\Pi_{G} x_{0}$ and $\Pi_{C_{n}} x_{0}$ are well defined.

(II) We prove that $\left\{x_{n}\right\}$ is a bounded sequence in $C$.

By the definition of $C_{n}$, we have $x_{n}=\prod_{C_{n}} x_{0}$ for all $n \geq 0$. It follows from Lemma 2.2(a) that

$$
\begin{aligned}
\phi\left(x_{n}, x_{0}\right) & =\phi\left(\Pi_{C_{n}} x_{0}, x_{0}\right) \leq \phi\left(u, x_{0}\right)-\phi\left(u, \Pi_{C_{n}} x_{0}\right) \\
& \leq \phi\left(u, x_{0}\right), \quad \forall n \geq 0, u \in G .
\end{aligned}
$$

This implies that $\left\{\phi\left(x_{n}, x_{0}\right)\right\}$ is bounded. By virtue of (2.4), $\left\{x_{n}\right\}$ is bounded. Denote by

$$
M=\sup _{n \geq 0}\left\{\left\|x_{n}\right\|\right\}<\infty .
$$

In view of the structure of $\left\{C_{n}\right\}$, we have $C_{n+1} \subset C_{n}, x_{n}=\Pi_{C_{n}} x_{0}$, and $x_{n+1}=\Pi_{C_{n+1}} x_{0}$. This implies that $x_{n+1} \in C_{n}$ and

$$
\phi\left(x_{n}, x_{0}\right) \leq \phi\left(x_{n+1}, x_{0}\right), \quad \forall n \geq 1 .
$$

Therefore, $\left\{\phi\left(x_{n}, x_{0}\right)\right\}$ is convergent. Without loss of generality, we can assume that

$$
\lim _{n \rightarrow \infty} \phi\left(x_{n}, x_{0}\right)=r \geq 0
$$

(III) Next, we prove that $G:=\bigcap_{i=1}^{\infty} F\left(S_{i}\right) \bigcap\left(\bigcap_{i=1}^{N} \Omega\left(\Theta_{i}, \psi\right)\right) \subset C_{n}$ for all $n \geq 0$. 
Indeed, it is obvious that $G \subset C_{0}=C$. Suppose that $G \subset C_{n}$ for some $n \geq 0$. Since $u_{n}^{(N)}=K_{r_{n}}^{\Theta_{N}} K_{r_{n}}^{\Theta_{N-1}} \cdots K_{r_{n}}^{\Theta_{2}} K_{r_{n}}^{\Theta_{1}} y_{n}$, by Lemma 2.10 and Remark 2.6, $K_{r_{n}}^{\Theta_{i}}$ is quasi- $\phi$ asymptotically nonexpansive. Since $E$ is uniformly smooth, $E^{*}$ is uniformly convex. For any given $u \in G \subset C_{n}$ and for any positive integer $j>0$, from Lemma 2.7 we have

$$
\begin{aligned}
& \phi\left(u, u_{n}^{(N)}\right)=\phi\left(u, K_{r_{n}}^{\Theta_{N}} K_{r_{n}}^{\Theta_{N-1}} \cdots K_{r_{n}}^{\Theta_{2}} K_{r_{n}}^{\Theta_{1}} y_{n}\right) \leq \phi\left(u, y_{n}\right) \\
& =\phi\left(u, J^{-1}\left(\alpha_{n} J z_{n}+\left(1-\alpha_{n}\right) J x_{n}\right)\right) \\
& \leq\|u\|^{2}-2\left\langle u, \alpha_{n} J z_{n}+\left(1-\alpha_{n}\right) J x_{n}\right\rangle+\left\|\alpha_{n} J z_{n}+\left(1-\alpha_{n}\right) J x_{n}\right\|^{2} \\
& \leq\|u\|^{2}-2\left\langle u, \alpha_{n} J z_{n}+\left(1-\alpha_{n}\right) J x_{n}\right\rangle+\alpha_{n}\left\|J z_{n}\right\|^{2}+\left(1-\alpha_{n}\right)\left\|J x_{n}\right\|^{2} \\
& =\|u\|^{2}-2\left\langle u, \alpha_{n} J z_{n}+\left(1-\alpha_{n}\right) J x_{n}\right\rangle+\alpha_{n}\left\|z_{n}\right\|^{2}+\left(1-\alpha_{n}\right)\left\|x_{n}\right\|^{2} \\
& =\alpha_{n} \phi\left(u, z_{n}\right)+\left(1-\alpha_{n}\right) \phi\left(u, x_{n}\right) \\
& =\alpha_{n} \phi\left(u, J^{-1}\left(\alpha_{n, 0} J x_{n}+\sum_{i=1}^{\infty} \alpha_{n, i} J S_{i}^{n} x_{n}\right)\right)+\left(1-\alpha_{n}\right) \phi\left(u, x_{n}\right) \\
& =\alpha_{n}\left(\|u\|^{2}-2 \alpha_{n, 0}\left\langle u, J x_{n}\right\rangle-2 \sum_{i=1}^{\infty} \alpha_{n, i}\left\langle u, J S_{i}^{n} x_{n}\right\rangle+\left\|\alpha_{n, 0} J x_{n}+\sum_{i=1}^{\infty} \alpha_{n, i} J S_{i}^{n} x_{n}\right\|^{2}\right) \\
& +\left(1-\alpha_{n}\right) \phi\left(u, x_{n}\right) \\
& \leq \alpha_{n}\left(\|u\|^{2}-2 \alpha_{n, 0}\left\langle u, J x_{n}\right\rangle-2 \sum_{i=1}^{\infty} \alpha_{n, i}\left\langle u, J S_{i}^{n} x_{n}\right\rangle+\alpha_{n, 0}\left\|J x_{n}\right\|^{2}\right. \\
& \left.+\sum_{i=1}^{\infty} \alpha_{n, i}\left\|J S_{i}^{n} x_{n}\right\|^{2}-\alpha_{n, 0} \alpha_{n, j} g\left(\left\|J x_{n}-J S_{j}^{n} x_{n}\right\|\right)\right)+\left(1-\alpha_{n}\right) \phi\left(u, x_{n}\right) \\
& \leq \alpha_{n}\left(\|u\|^{2}-2 \alpha_{n, 0}\left\langle u, J x_{n}\right\rangle-2 \sum_{i=1}^{\infty} \alpha_{n, i}\left\langle u, J S_{i}^{n} x_{n}\right\rangle+\alpha_{n, 0}\left\|x_{n}\right\|^{2}\right. \\
& \left.+\sum_{i=1}^{\infty} \alpha_{n, i}\left\|S_{i}^{n} x_{n}\right\|^{2}-\alpha_{n, 0} \alpha_{n, j} g\left(\left\|J x_{n}-J S_{j}^{n} x_{n}\right\|\right)\right)+\left(1-\alpha_{n}\right) \phi\left(u, x_{n}\right) \\
& =\alpha_{n}\left(\alpha_{n, 0} \phi\left(u, x_{n}\right)+\sum_{i=1}^{\infty} \alpha_{n, i} \phi\left(u, S_{i}^{n} x_{n}\right)-\alpha_{n, 0} \alpha_{n, j} g\left(\left\|J x_{n}-J S_{j}^{n} x_{n}\right\|\right)\right) \\
& +\left(1-\alpha_{n}\right) \phi\left(u, x_{n}\right) \\
& \leq \alpha_{n}\left(\alpha_{n, 0} \phi\left(u, x_{n}\right)+\sum_{i=1}^{\infty} \alpha_{n, i} k_{n} \phi\left(u, x_{n}\right)-\alpha_{n, 0} \alpha_{n, j} g\left(\left\|J x_{n}-J S_{j}^{n} x_{n}\right\|\right)\right) \\
& +\left(1-\alpha_{n}\right) \phi\left(u, x_{n}\right) \\
& \leq \alpha_{n}\left(k_{n} \phi\left(u, x_{n}\right)-\alpha_{n, 0} \alpha_{n, j} g\left(\left\|J x_{n}-J S_{j}^{n} x_{n}\right\|\right)\right)+\left(1-\alpha_{n}\right) \phi\left(u, x_{n}\right) \\
& \leq \alpha_{n}\left(\phi\left(u, x_{n}\right)+\sup _{u \in G}\left(k_{n}-1\right) \phi\left(u, x_{n}\right)-\alpha_{n, 0} \alpha_{n, j} g\left(\left\|J x_{n}-J S_{j}^{n} x_{n}\right\|\right)\right) \\
& +\left(1-\alpha_{n}\right) \phi\left(u, x_{n}\right) \\
& =\phi\left(u, x_{n}\right)+\alpha_{n} \xi_{n}-\alpha_{n} \alpha_{n, 0} \alpha_{n, j} g\left(\left\|J x_{n}-J S_{i}^{n} x_{n}\right\|\right) \\
& \leq \phi\left(u, x_{n}\right)+\xi_{n} \text {. }
\end{aligned}
$$


Hence $u \in C_{n+1}$, and so $G \subset C_{n}$ for all $n \geq 0$. By the way, from the definition of $\left\{\xi_{n}\right\},(2.4)$, and (3.6), it is easy to see that

$$
\xi_{n}=\sup _{u \in G}\left(k_{n}-1\right) \phi\left(u, x_{n}\right) \leq \sup _{u \in G}\left(k_{n}-1\right)(\|u\|+M)^{2} \longrightarrow 0 \quad(\text { as } n \longrightarrow \infty) .
$$

(IV) Now, we prove that $\left\{x_{n}\right\}$ converges strongly to some point $p \in G:=\bigcap_{i=1}^{\infty} F\left(S_{i}\right) \cap \Omega$.

First, we prove that $\left\{x_{n}\right\}$ converges strongly to some point $p \in \bigcap_{i=1}^{\infty} F\left(S_{i}\right)$.

In fact, since $\left\{x_{n}\right\}$ is bounded in $C$ and $E$ is reflexive, there exists a subsequence $\left\{x_{n_{i}}\right\} \subset$ $\left\{x_{n}\right\}$ such that $x_{n_{i}} \rightarrow p$. Again since $C_{n}$ is closed and convex for each $n \geq 1$, it is weakly closed, and so $p \in C_{n}$ for each $n \geq 0$. Since $x_{n}=\Pi_{C_{n}} x_{0}$, from the definition of $\Pi_{C_{n}}$, we have

$$
\phi\left(x_{n_{i}}, x_{0}\right) \leq \phi\left(p, x_{0}\right), \quad n \geq 0 .
$$

Since

$$
\begin{aligned}
\liminf _{n_{i} \rightarrow \infty} \phi\left(x_{n_{i}}, x_{0}\right) & =\liminf _{n_{i} \rightarrow \infty}\left\{\left\|x_{n_{i}}\right\|^{2}-2\left\langle x_{n_{i}}, J x_{0}\right\rangle+\left\|x_{0}\right\|^{2}\right\} \\
& \geq\|p\|^{2}-2\left\langle p, J x_{0}\right\rangle+\left\|x_{0}\right\|^{2}=\phi\left(p, x_{0}\right),
\end{aligned}
$$

we have

$$
\phi\left(p, x_{0}\right) \leq \liminf _{n_{i} \rightarrow \infty} \phi\left(x_{n_{i}}, x_{0}\right) \leq \limsup _{n_{i} \rightarrow \infty} \phi\left(x_{n_{i}}, x_{0}\right) \leq \phi\left(p, x_{0}\right) .
$$

This implies that $\lim _{n_{i} \rightarrow \infty} \phi\left(x_{n_{i}}, x_{0}\right)=\phi\left(p, x_{0}\right)$, that is, $\left\|x_{n_{i}}\right\| \rightarrow\|p\|$. In view of the Kadec-Klee property of $E$, we obtain that $\lim _{n \rightarrow \infty} x_{n_{i}}=p$.

Now we prove that $x_{n} \rightarrow p(n \rightarrow \infty)$. In fact, if there exists a subsequence $\left\{x_{n_{j}}\right\} \subset$ $\left\{x_{n}\right\}$ such that $x_{n_{j}} \rightarrow q$, then we have

$$
\begin{aligned}
\phi(p, q) & =\lim _{n_{i} \rightarrow \infty, n_{j} \rightarrow \infty} \phi\left(x_{n_{i}}, x_{n_{j}}\right) \leq \lim _{n_{i} \rightarrow \infty, n_{j} \rightarrow \infty} \phi\left(x_{n_{i}} x_{0}\right)-\phi\left(\Pi_{C_{n_{j}}} x_{0}, x_{0}\right) \\
& =\lim _{n_{i} \rightarrow \infty, n_{j} \rightarrow \infty} \phi\left(x_{n_{i}}, x_{0}\right)-\phi\left(x_{n_{j}}, x_{0}\right)=0 \quad \text { (by (3.8)). }
\end{aligned}
$$

Therefore we have $p=q$. This implies that

$$
\lim _{n \rightarrow \infty} x_{n}=p
$$


Now we prove that $p \in \bigcap_{i=1}^{\infty} F\left(S_{i}\right)$. In fact, by the construction of $C_{n}$, we have that $C_{n+1} \subset C_{n}$ and $x_{n+1}=\Pi_{C_{n+1}} x_{0}$. Therefore, by Lemma 2.2(a) we have

$$
\begin{aligned}
\phi\left(x_{n+1}, x_{n}\right) & =\phi\left(x_{n+1}, \Pi_{C_{n}} x_{0}\right) \\
& \leq \phi\left(x_{n+1}, x_{0}\right)-\phi\left(\Pi_{C_{n}} x_{0}, x_{0}\right) \\
& =\phi\left(x_{n+1}, x_{0}\right)-\phi\left(x_{n}, x_{0}\right) \longrightarrow 0 \quad(\text { as } n \longrightarrow \infty)
\end{aligned}
$$

In view of $x_{n+1} \in C_{n}$ and noting the construction of $C_{n+1}$ we obtain that

$$
\phi\left(x_{n+1}, u_{n}^{(N)}\right) \leq \phi\left(x_{n+1}, x_{n}\right)+\xi_{n} \longrightarrow 0 \quad(\text { as } n \longrightarrow \infty)
$$

From (2.4) it yields $\left(\left\|x_{n+1}\right\|-\left\|u_{n}^{(N)}\right\|\right)^{2} \rightarrow 0$. Since $\left\|x_{n+1}\right\| \rightarrow\|p\|$, we have

$$
\left\|u_{n}^{(N)}\right\| \longrightarrow\|p\| \quad(\text { as } n \longrightarrow \infty) .
$$

Hence we have

$$
\left\|J u_{n}^{(N)}\right\| \longrightarrow\|J p\| \quad(\text { as } n \longrightarrow \infty)
$$

This implies that $\left\{J u_{n}^{(N)}\right\}$ is bounded in $E^{*}$. Since $E$ is reflexive, and so $E^{*}$ is reflexive, there exists a subsequence $\left\{J u_{n_{i}}^{(N)}\right\} \subset\left\{J u_{n}^{(N)}\right\}$ such that $J u_{n_{i}}^{(N)} \rightarrow p_{0} \in E^{*}$. In view of the reflexive of $E$, we see that $J(E)=E^{*}$. Hence there exists $x \in E$ such that $J x=p_{0}$. Since

$$
\begin{aligned}
\phi\left(x_{n_{i}}, u_{n_{i}}^{(N)}\right) & =\left\|x_{n_{i}}\right\|^{2}-2\left\langle x_{n_{i}} J u_{n_{i}}^{(N)}\right\rangle+\left\|u_{n_{i}}^{(N)}\right\|^{2} \\
& =\left\|x_{n_{i}}\right\|^{2}-2\left\langle x_{n_{i}} J u_{n_{i}}^{(N)}\right\rangle+\left\|J u_{n_{i}}^{(N)}\right\|^{2},
\end{aligned}
$$

taking $\liminf \operatorname{in}_{n \rightarrow \infty}$ on both sides of above equality and in view of the weak lower semicontinuity of norm $\|\cdot\|$, it yields that

$$
\begin{aligned}
0 & \geq\|p\|^{2}-2\left\langle p, p_{0}\right\rangle+\left\|p_{0}\right\|^{2}=\|p\|^{2}-2\langle p, J x\rangle+\|J x\|^{2} \\
& =\|p\|^{2}-2\langle p, J x\rangle+\|x\|^{2}=\phi(p, x) .
\end{aligned}
$$

That is, $p=x$. This implies that $p_{0}=J p$, and so $J u_{n}^{(N)} \rightarrow J p$. It follows from (3.19) and the Kadec-Klee property of $E^{*}$ that $J u_{n_{i}}^{(N)} \rightarrow J p($ as $n \rightarrow \infty)$. Noting that $J^{-1}: E^{*} \rightarrow E$ is normweak continuous, it yields that $u_{n_{i}}^{(N)} \rightarrow p$. It follows from (3.18) and the Kadec-Klee property of $E$ that $\lim _{n_{i} \rightarrow \infty} u_{n_{i}}^{(N)}=p$.

By the similar way as given in the proof of (3.15), we can also prove that

$$
\lim _{n \rightarrow \infty} u_{n}^{(N)}=p
$$


From (3.15) and (3.22) we have that

$$
\left\|x_{n}-u_{n}^{(N)}\right\| \longrightarrow 0 \quad(\text { as } n \longrightarrow \infty)
$$

Since $J$ is uniformly continuous on any bounded subset of $E$, we have

$$
\left\|J x_{n}-J u_{n}^{(N)}\right\| \longrightarrow 0 \quad(\text { as } n \longrightarrow \infty)
$$

For any $j \geq 1$ and any $u \in G$, it follows from (3.9), (3.15), and (3.22) that

$$
\alpha_{n} \alpha_{n, 0} \alpha_{n, j} g\left(\left\|J x_{n}-J S_{i}^{n} x_{n}\right\|\right) \leq \phi\left(u, x_{n}\right)-\phi\left(u, u_{n}^{(N)}\right)+\alpha_{n} \xi_{n}
$$

Since

$$
\begin{aligned}
\phi\left(u, x_{n}\right)-\phi\left(u, u_{n}^{(N)}\right) & =\left\|x_{n}\right\|^{2}-\left\|u_{n}^{(N)}\right\|^{2}-2\left\langle u, J x_{n}-J u_{n}^{(N)}\right\rangle \\
& \leq\left|\left\|x_{n}\right\|^{2}-\left\|u_{n}^{(N)}\right\|^{2}\right|+2\|u\| \cdot\left\|J x_{n}-J u_{n}^{(N)}\right\| \\
& \leq\left\|x_{n}-u_{n}^{(N)}\right\|\left(\left\|x_{n}\right\|+\left\|u_{n}^{(N)}\right\|\right)+2\|u\| \cdot\left\|J x_{n}-J u_{n}^{(N)}\right\|,
\end{aligned}
$$

From (3.23) and (3.24), it follows that

$$
\phi\left(u, x_{n}\right)-\phi\left(u, u_{n}^{(N)}\right) \longrightarrow 0 \quad(\text { as } n \longrightarrow \infty)
$$

In view of conditions (b) $\liminf _{n \rightarrow \infty} \alpha_{n, 0} \alpha_{n, j}>0$ and (c) $\alpha_{n} \geq \alpha>0$, we see that

$$
g\left(\left\|J x_{n}-J S_{i}^{n} x_{n}\right\|\right) \longrightarrow 0 \quad(\text { as } n \longrightarrow \infty)
$$

It follows from the property of $g$ that

$$
\left\|J x_{n}-J S_{i}^{n} x_{n}\right\| \longrightarrow 0 \quad(\text { as } n \longrightarrow \infty)
$$

Since $x_{n} \rightarrow p$ and $J$ is uniformly continuous, it yields $J x_{n} \rightarrow J p$. Hence from (3.29) we have

$$
J S_{j}^{n} x_{n} \longrightarrow J p \quad(\text { as } n \longrightarrow \infty)
$$

Since $J^{-1}: E^{*} \rightarrow E$ is norm-weak continuous, it follows that

$$
S_{j}^{n} x_{n} \rightarrow p \quad(\text { for each } j \geq 1)
$$


On the other hand, for each $j \geq 1$ we have

$$
\left|\left\|S_{j}^{n} x_{n}\right\|-\|p\|\right|=\left|\left\|J\left(S_{j}^{n} x_{n}\right)\right\|-\|J p\|\right| \leq\left\|J S_{j}^{n} x_{n}-J p\right\| \longrightarrow 0 \quad(\text { as } n \longrightarrow \infty) .
$$

This together with (3.31) shows that

$$
S_{j}^{n} x_{n} \longrightarrow p \quad(\text { for each } j \geq 1)
$$

Furthermore, by the assumption that for each $j \geq 1, S_{j}$ is uniformly $L_{i}$-Lipschitz continuous, hence we have

$$
\begin{aligned}
\left\|S_{j}^{n+1} x_{n}-S_{j}^{n} x_{n}\right\| & \leq\left\|S_{j}^{n+1} x_{n}-S_{j}^{n+1} x_{n+1}\right\|+\left\|S_{j}^{n+1} x_{n+1}-x_{n+1}\right\|+\left\|x_{n+1}-x_{n}\right\|+\left\|x_{n}-S_{j}^{n} x_{n}\right\| \\
& \leq\left(L_{j}+1\right)\left\|x_{n+1}-x_{n}\right\|+\left\|S_{j}^{n+1} x_{n+1}-x_{n+1}\right\|+\left\|x_{n}-S_{j}^{n} x_{n}\right\| .
\end{aligned}
$$

This together with (3.15) and (3.33) yields $\left\|S_{j}^{n+1} x_{n}-S_{j}^{n} x_{n}\right\| \rightarrow 0$ (as $\left.n \rightarrow \infty\right)$. Hence from (3.33) we have $S_{j}^{n+1} x_{n} \rightarrow p$, that is, $S_{j} S_{j}^{n} x_{n} \rightarrow p$. In view of (3.33) and the closeness of $S_{j}$, it yields that $S_{j} p=p$, for all $j \geq 1$. This implies that $p \in \bigcap_{i=1}^{\infty} F\left(S_{i}\right)$.

Next, we prove that $p \in \bigcap_{i=1}^{N} \Omega\left(\Theta_{i}, \psi\right)$. Since $u_{n}^{(N)}=K_{r_{n}}^{\Theta_{N}} u_{n}^{(N-1)}$, from (2.18), (3.9), and (3.27), we have

$$
\begin{aligned}
\phi\left(u_{n}^{(N)}, u_{n}^{(N-1)}\right) & =\phi\left(K_{r_{n}}^{\Theta_{N}} u_{n}^{(N-1)}, u_{n}^{(N-1)}\right) \\
& \leq \phi\left(u, u_{n}^{(N-1)}\right)-\phi\left(u, K_{r_{n}}^{\Theta_{N}} u_{n}^{(N-1)}\right) \\
& \leq \phi\left(u, x_{n}\right)+\xi_{n}-\phi\left(u, K_{r_{n}}^{\Theta_{N}} u_{n}^{(N-1)}\right) \\
& =\phi\left(u, x_{n}\right)+\xi_{n}-\phi\left(u, u_{n}^{(N)}\right) \longrightarrow 0 \quad(\text { as } n \longrightarrow \infty) .
\end{aligned}
$$

From (2.4) it yields $\left(\left\|u_{n}^{(N)}\right\|-\left\|u_{n}^{(N-1)}\right\|\right)^{2} \rightarrow 0$. Since $\left\|u_{n}^{(N)}\right\| \rightarrow\|p\|$, we have

$$
\left\|u_{n}^{(N-1)}\right\| \longrightarrow\|p\| \quad(\text { as } n \longrightarrow \infty)
$$

Hence we have

$$
\left\|J u_{n}^{(N-1)}\right\| \longrightarrow\|J p\| \quad(\text { as } n \longrightarrow \infty)
$$


This implies that $\left\{J u_{n}^{(N-1)}\right\}$ is bounded in $E^{*}$. Since $E$ is reflexive, and so $E^{*}$ is reflexive, there exists a subsequence $\left\{J u_{n_{i}}^{(N-1)}\right\} \subset\left\{J u_{n}^{(N-1)}\right\}$ such that $J u_{n_{i}}^{(N-1)} \rightarrow p_{0} \in E^{*}$. In view of the reflexive of $E$, we see that $J(E)=E^{*}$. Hence there exists $x \in E$ such that $J x=p_{0}$. Since

$$
\begin{aligned}
\phi\left(u_{n_{i}}^{(N)}, u_{n_{i}}^{(N-1)}\right) & =\left\|u_{n_{i}}^{(N)}\right\|^{2}-2\left\langle u_{n_{i}}^{(N)}, J u_{n_{i}}^{(N-1)}\right\rangle+\left\|u_{n_{i}}^{(N-1)}\right\|^{2} \\
& =\left\|u_{n_{i}}^{(N)}\right\|^{2}-2\left\langle u_{n_{i}}^{(N)}, J u_{n_{i}}^{(N-1)}\right\rangle+\left\|J u_{n_{i}}^{(N-1)}\right\|^{2},
\end{aligned}
$$

taking $\liminf _{n \rightarrow \infty}$ on both sides of equality above and in view of the weak lower semicontinuity of norm $\|\cdot\|$, it yields that

$$
\begin{aligned}
0 & \geq\|p\|^{2}-2\left\langle p, p_{0}\right\rangle+\left\|p_{0}\right\|^{2}=\|p\|^{2}-2\langle p, J x\rangle+\|J x\|^{2} \\
& =\|p\|^{2}-2\langle p, J x\rangle+\|x\|^{2}=\phi(p, x) .
\end{aligned}
$$

That is, $p=x$. This implies that $p_{0}=J p$, and so $J u_{n_{i}}^{(N-1)} \rightarrow J p$. It follows from (3.37) and the Kadec-Klee property of $E^{*}$ that $J u_{n}^{(N-1)} \rightarrow J p($ as $n \rightarrow \infty)$. Note that $J^{-1}: E^{*} \rightarrow E$ is hemicontinuous, it yields that $u_{n_{i}}^{(N-1)} \rightarrow p$. It follows from (3.36) and the Kadec-Klee property of $E$ that $\lim _{n_{i} \rightarrow \infty} u_{n_{i}}^{(N-1)}=p$.

By the similar way as given in the proof of (3.15), we can also prove that

$$
\lim _{n \rightarrow \infty} u_{n}^{(N-1)}=p .
$$

From (3.22) and (3.40) we have that

$$
\left\|u_{n}^{(N)}-u_{n}^{(N-1)}\right\| \longrightarrow 0 \quad(\text { as } n \longrightarrow \infty)
$$

Since $J$ is uniformly continuous on any bounded subset of $E$, we have

$$
\left\|J u_{n}^{(N)}-J u_{n}^{(N-1)}\right\| \longrightarrow 0 \quad(\text { as } n \longrightarrow \infty) .
$$

Since

$$
u_{n}^{(i)}=K_{r_{n}}^{\Theta_{i}} u_{n}^{(i-1)}, \quad i=2,3, \ldots, N, \quad u_{n}^{(1)}=K_{r_{n}}^{\Theta_{1}} y_{n}
$$

by the similar way as above, we can also prove that

$$
\begin{aligned}
\left\|u_{n}^{(i)}-u_{n}^{(i-1)}\right\| & \longrightarrow 0, \\
\left\|J u_{n}^{(i)}-J u_{n}^{(i-1)}\right\| & \longrightarrow 0, \\
\left\|y_{n}-u_{n}^{(1)}\right\| & \longrightarrow 0, \\
\left\|J y_{n}-J u_{n}^{(1)}\right\| & \longrightarrow 0 \quad(\text { as } n \longrightarrow \infty), i=2,3, \ldots, N .
\end{aligned}
$$


From (3.44) and the assumption that $r_{n} \geq d$, for all $n \geq 0$, we have

$$
\lim _{n \rightarrow \infty} \frac{\left\|J u_{n}^{(i)}-J u_{n}^{(i-1)}\right\|}{r_{n}}=0, \quad \lim _{n \rightarrow \infty} \frac{\left\|J y_{n}-J u_{n}^{(1)}\right\|}{r_{n}}=0, \quad i=2,3, \ldots, N .
$$

Now, we define functions $H_{i}: C \times C \rightarrow \mathbb{R}, i=1,2, \ldots, N$ by

$$
H_{i}(x, y)=\Theta_{i}(x, y)+\langle A x, y-x\rangle+\psi(y)-\psi(x), \quad \forall x, y \in C
$$

By Lemma 2.9, we know that the function $H_{i}$ satisfies conditions $\left(A_{1}\right)-\left(A_{4}\right)$. Since

$$
\begin{aligned}
& H_{i}\left(u_{n}^{(i)}, y\right)+\frac{1}{r_{n}}\left\langle y-u_{n}^{(i)}, J u_{n}^{(i)}-J u_{n}^{(i-1)}\right\rangle \geq 0, \\
& H_{1}\left(u_{n}^{(1)}, y\right)+\frac{1}{r_{n}}\left\langle y-u_{n}^{(1)}, J u_{n}^{(1)}-J y_{n}\right\rangle \geq 0, \quad \forall y \in C,
\end{aligned}
$$

by condition $\left(A_{2}\right)$, we have

$$
\begin{aligned}
& \frac{1}{r_{n}}\left\langle y-u_{n}^{(i)}, J u_{n}^{(i)}-J u_{n}^{(i-1)}\right\rangle \geq-H_{i}\left(u_{n}^{(i)}, y\right) \geq H_{i}\left(y, u_{n}^{(i)}\right) \\
& \frac{1}{r_{n}}\left\langle y-u_{n}^{(1)}, J u_{n}^{(1)}-J y_{n}\right\rangle \geq-H_{1}\left(u_{n}^{(1)}, y\right) \geq H_{1}\left(y, u_{n}^{(1)}\right), \quad \forall y \in C .
\end{aligned}
$$

By the assumption that $y \mapsto H_{i}(x, y)$ is convex and lower semicontinuous, letting $n \rightarrow \infty$ in (3.48), from (3.45) and (3.48), for each $i$, we have $H_{\mathrm{i}}(y, p) \leq 0$, for all $y \in C$.

For $t \in(0,1]$ and $y \in C$, letting $y_{t}=t y+(1-t) p$, there are $y_{t} \in C$ and $H_{i}\left(y_{t}, p\right) \leq 0$. By conditions $\left(A_{1}\right)$ and $\left(A_{4}\right)$, we have

$$
0=H_{i}\left(y_{t}, y_{t}\right) \leq t H_{i}\left(y_{t}, y\right)+(1-t) H_{i}\left(y_{t}, p\right) \leq t H_{i}\left(y_{t}, y\right)
$$

Dividing both sides of the above equation by $t$, we have $H_{i}\left(y_{t}, y\right) \geq 0$,for all $y \in C$. Letting $t \downarrow 0$, from condition $\left(A_{3}\right)$, we have $H_{i}(p, y) \geq 0$, for all $y \in C$, that is, $p \in \bigcap_{i=1}^{N} \Omega\left(\Theta_{i}, \psi\right)$, that is, $p \in \Omega$, and $p \in \bigcap_{i=1}^{\infty} F\left(S_{i}\right) \bigcap \Omega$.

(V) Now, we prove $x_{n} \rightarrow \Pi_{\bigcap_{i=1}^{\infty} F\left(S_{i}\right) \cap \Omega} x_{0}$.

Let $w=\prod_{\bigcap_{i=1}^{\infty} F\left(S_{i}\right) \cap \Omega} x_{0}$. From $w \in \bigcap_{i=1}^{\infty} F\left(S_{i}\right) \bigcap \Omega \subset C_{n+1}$ and $x_{n+1}=\Pi_{C_{n+1}} x_{0}$, we have $\phi\left(x_{n+1}, x_{0}\right) \leq \phi\left(w, x_{0}\right)$, for all $n \geq 0$. This implies that

$$
\phi\left(p, x_{0}\right)=\lim _{n \rightarrow \infty} \phi\left(x_{n}, x_{0}\right) \leq \phi\left(w, x_{0}\right)
$$

By the definition of $\Pi_{\bigcap_{i=1}^{\infty} F\left(S_{i}\right) \cap \Omega} x_{0}$ and (3.50), we have $p=w$. Therefore, $x_{n} \rightarrow$ $\Pi_{\bigcap_{i=1}^{\infty} F\left(S_{i}\right) \cap \Omega} x_{0}$. This completes the proof of Theorem 3.1. 
Theorem 3.2. Let $E$ be a uniformly smooth and strictly convex Banach space with Kleac-Klee property and $C$ a nonempty closed convex subset of $E$. Let $A: C \rightarrow E^{*}$ be a continuous and monotone mapping, $\psi: C \rightarrow \mathbb{R}$ a lower semicontinuous and convex function, and $\left\{\Theta_{i}: C \times C \rightarrow \mathbb{R}, i=1,2, \ldots, N\right\}$ a finite family of bifunction satisfying conditions $\left(A_{1}\right)-\left(A_{4}\right)$. Let $\left\{S_{i}\right\}_{i=1}^{\infty}: C \rightarrow C$ be an infinite family of closed and quasi- $\phi$-nonexpansive mappings. Suppose that $G:=\bigcap_{i=1}^{\infty} F\left(S_{i}\right) \cap \Omega \neq \emptyset$, where $\Omega=\bigcap_{i=1}^{N} \Omega\left(\Theta_{i}, \psi\right)$. Let $\left\{x_{n}\right\},\left\{y_{n}\right\},\left\{z_{n}\right\}$, and $\left\{u_{n}^{(k)}\right\}, k=1,2, \ldots, N$, be the sequences generated by

$$
\begin{gathered}
x_{0} \in C, \quad C_{0}=C, \\
z_{n}=J^{-1}\left(\alpha_{n, 0} J x_{n}+\sum_{i=1}^{\infty} \alpha_{n, i} J S_{i}^{n} x_{n}\right), \\
y_{n}=J^{-1}\left(\alpha_{n}+\left(1-\alpha_{n}\right) J z_{n}\right), \\
u_{n}^{(N)} \in C \text { such that, } \forall y \in C, \\
\Theta_{N}\left(u_{n}^{(N)}, y\right)+\left\langle A u_{n}^{(N)}, y-u_{n}^{(N)}\right\rangle+\psi(y)-\psi\left(u_{n}^{(N)}\right)+\frac{1}{r_{n}}\left\langle y-u_{n}^{(N)}, J u_{n}^{(N)}-J u_{n}^{(N-1)}\right\rangle \geq 0, \\
\Theta_{N-1}\left(u_{n}^{(N-1)}, y\right)+\left\langle A u_{n}^{(N-1)}, y-u_{n}^{(N-1)}\right\rangle+\psi(y)-\psi\left(u_{n}^{(N-1)}\right) \\
+\frac{1}{r_{n}}\left\langle y-u_{n}^{(N-1)}, J u_{n}^{(N-1)}-J u_{n}^{(N-2)}\right\rangle \geq 0, \\
\vdots \\
\Theta_{1}\left(u_{n}^{(1)}, y\right)+\left\langle A u_{n}^{(1)}, y-u_{n}^{(1)}\right\rangle+\psi(y)-\psi\left(u_{n}^{(1)}\right)+\frac{1}{r_{n}}\left\langle y-u_{n}^{(1)}, J u_{n}^{(1)}-J y_{n}\right\rangle \geq 0, \\
C_{n+1}=\left\{v \in C_{n}: \phi\left(v, u_{n}^{(N)}\right) \leq \phi\left(v, x_{n}\right)\right\}, \quad \forall n \geq 0, \\
x_{n+1}=\Pi_{C_{n+1}} x_{0},
\end{gathered}
$$

where $r_{n} \in[d, \infty)$ for some $d>0$ and for $i \geq 0,\left\{\alpha_{n, i}\right\},\left\{\alpha_{n}\right\}$ are sequences in $[0,1]$ satisfying the following conditions:

(a) $\sum_{i=0}^{\infty} \alpha_{n, i}=1$, for all $n \geq 0$;

(b) $\liminf _{n \rightarrow \infty} \alpha_{n, 0} \cdot \alpha_{n, i}>0$ for all $i \geq 1$;

(c) $0<\alpha \leq \alpha_{n}<1$ for some $\alpha \in(0,1)$.

Then $\left\{x_{n}\right\}$ converges strongly to $\Pi_{G} x_{0}$.

Proof. Since $\left\{S_{i}\right\}_{i=1}^{\infty}: C \rightarrow C$ is an infinite family of closed quasi- $\phi$-nonexpansive mappings, it is an infinite family of closed and uniformly quasi- $\phi$-asymptotically nonexpansive mappings with sequence $\left\{k_{n}=1\right\}$. Hence $\xi_{n}=\sup _{u \in G}\left(k_{n}-1\right) \phi\left(u, x_{n}\right)=0$. Therefore, the conditions appearing in Theorem 3.1- "G is bounded subset in $C^{\prime \prime}$ and for each $i \geq 1, S_{i}$ is uniformly $L_{i-}$ Lipschitz continuous - are of no use here. In fact, by the same methods as given in the proofs of (3.15), (3.22), (3.31), (3.37), and (3.42), we can prove that $x_{n} \rightarrow p, u_{n}^{(i)} \rightarrow p, y_{n} \rightarrow p$, and 
$S_{j} x_{n} \rightarrow p($ as $n \rightarrow \infty)$, for each $j \geq 1$, that is, $p \in \bigcap_{i=1}^{\infty} F\left(S_{i}\right) \cap \Omega$. Therefore, all conditions in Theorem 3.1 are satisfied. The conclusion of Theorem 3.2 is obtained from Theorem 3.1 immediately.

Remark 3.3. Theorems 3.1 and 3.2 improve and extend the corresponding results in [10-12, 18].

(a) For the framework of spaces, we extend the space from a uniformly smooth and uniformly convex Banach space to a uniformly smooth and strictly convex Banach space with the Kadec-Klee property (note that each uniformly convex Banach space must have Kadec-Klee property).

(b) For the mappings, we extend the mappings from nonexpansive mappings, relatively nonexpansive mappings, or quasi- $\phi$-nonexpansive mapping to an infinite family of quasi- $\phi$-asymptotically nonexpansive mappings.

(c) We extend a single generalized mixed equilibrium problem to a system of generalized mixed equilibrium problems.

\section{References}

[1] L.-C. Ceng and J.-C. Yao, "A hybrid iterative scheme for mixed equilibrium problems and fixed point problems," Journal of Computational and Applied Mathematics, vol. 214, no. 1, pp. 186-201, 2008.

[2] F. E. Browder, "Existence and approximation of solutions of nonlinear variational inequalities," Proceedings of the National Academy of Sciences of the United States of America, vol. 56, pp. 1080-1086, 1966.

[3] W. Takahashi and K. Zembayashi, "Strong and weak convergence theorems for equilibrium problems and relatively nonexpansive mappings in Banach spaces," Nonlinear Analysis: Theory, Methods $\mathcal{E}$ Applications, vol. 70, no. 1, pp. 45-57, 2009.

[4] S. Takahashi and W. Takahashi, "Viscosity approximation methods for equilibrium problems and fixed point problems in Hilbert spaces," Journal of Mathematical Analysis and Applications, vol. 331, no. 1, pp. 506-515, 2007.

[5] X. L. Qin, M. Shang, and Y. F. Su, "A general iterative method for equilibrium problems and fixed point problems in Hilbert spaces," Nonlinear Analysis: Theory, Methods \& Applications, vol. 69, no. 11, pp. 3897-3909, 2008.

[6] S.-S. Chang, J. K. Kim, and X. R. Wang, "Modified block iterative algorithm for solving convex feasibility problems in Banach spaces," Journal of Inequalities and Applications, Article ID 869684, 14 pages, 2010.

[7] S. S. Zhan, "Existence and approximation of solutions of set-valued variational inclusions in Banach spaces," Applied Mathematics and Mechanics, vol. 30, no. 9, pp. 1105-1112, 2009.

[8] Y. Su, H.-K. Xu, and X. Zhang, "Strong convergence theorems for two countable families of weak relatively nonexpansive mappings and applications," Nonlinear Analysis: Theory, Methods $\mathcal{E}$ Applications, vol. 73, no. 12, pp. 3890-3906, 2010.

[9] H. Y. Zhou, G. Gao, and B. Tan, "Convergence theorems of a modified hybrid algorithm for a family of quasi- $\phi$-asymptotically nonexpansive mappings," Journal of Applied Mathematics and Computing, vol. 32, no. 2, pp. 453-464, 2010.

[10] S. Plubtieng and K. Ungchittrakool, "Hybrid iterative methods for convex feasibility problems and fixed point problems of relatively nonexpansive mappings in Banach spaces," Fixed Point Theory and Applications, Article ID 583082, 19 pages, 2008.

[11] S. Plubtieng and K. Ungchittrakool, "Strong convergence theorems of block iterative methods for a finite family of relatively nonexpansive mappings in Banach spaces," Journal of Nonlinear and Convex Analysis, vol. 8, no. 3, pp. 431-450, 2007.

[12] S.-S. Chang, H. W. J. Lee, and C. K. Chan, "A new method for solving equilibrium problem fixed point problem and variational inequality problem with application to optimization," Nonlinear Analysis: Theory, Methods E Applications, vol. 70, no. 9, pp. 3307-3319, 2009. 
[13] I. Cioranescu, Geometry of Banach Spaces, Duality Mappings and Nonlinear Problems, vol. 62 of Mathematics and Its Applications, Kluwer Academic Publishers, Dordrecht,The Netherlands, 1990.

[14] Y. I. Alber, "Metric and generalized projection operators in Banach spaces: properties and applications," in Theory and Applications of Nonlinear Operators of Accretive and Monotone Type, A. Kartsatos, Ed., vol. 178 of Lecture Notes in Pure and Applied Mathematics, pp. 15-50, Marcel Dekker, New York, NY, USA, 1996.

[15] S. Kamimura and W. Takahashi, "Strong convergence of a proximal-type algorithm in a Banach space," SIAM Journal on Optimization, vol. 13, no. 3, pp. 938-945, 2002.

[16] S.-Y. Matsushita and W. Takahashi, "A strong convergence theorem for relatively nonexpansive mappings in a Banach space," Journal of Approximation Theory, vol. 134, no. 2, pp. 257-266, 2005.

[17] E. Blum and W. Oettli, "From optimization and variational inequalities to equilibrium problems," The Mathematics Student, vol. 63, no. 1-4, pp. 123-145, 1994.

[18] A. Aleyner and S. Reich, "Block-iterative algorithms for solving convex feasibility problems in Hilbert and in Banach spaces," Journal of Mathematical Analysis and Applications, vol. 343, no. 1, pp. 427-435, 2008. 


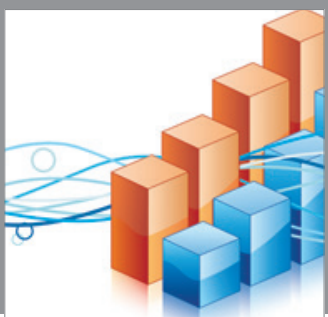

Advances in

Operations Research

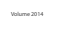

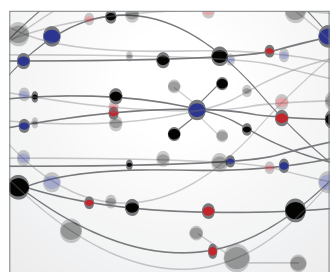

\section{The Scientific} World Journal
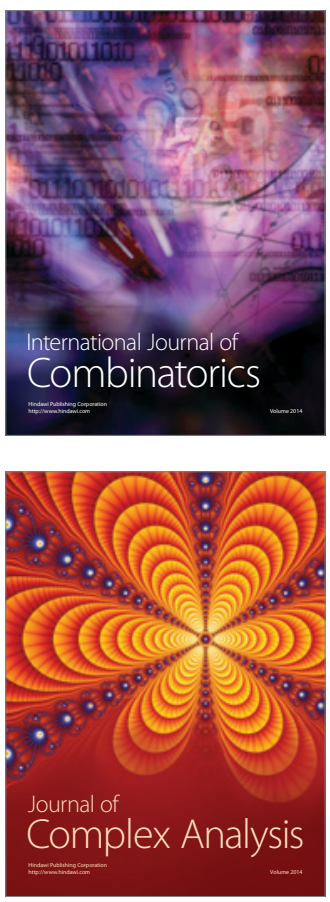

International Journal of

Mathematics and

Mathematical

Sciences
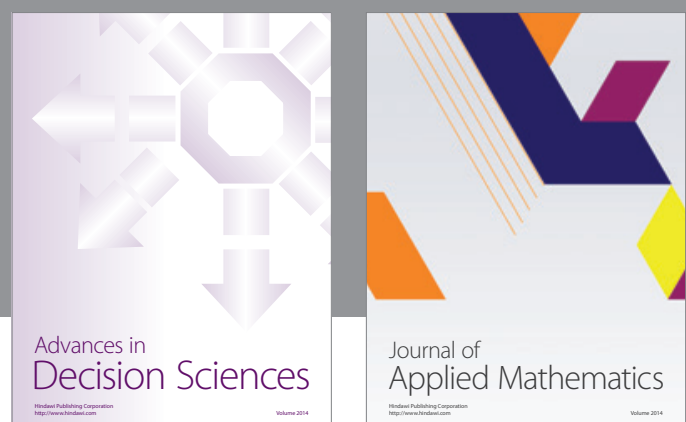

Journal of

Applied Mathematics
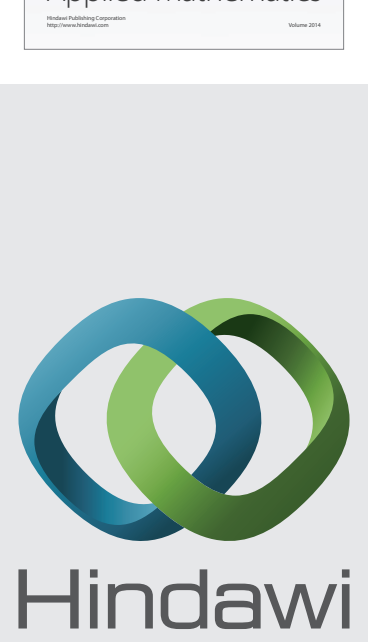

Submit your manuscripts at http://www.hindawi.com
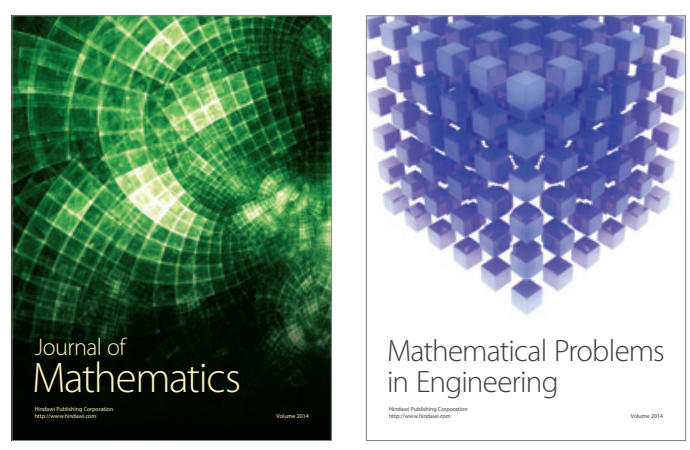

Mathematical Problems in Engineering
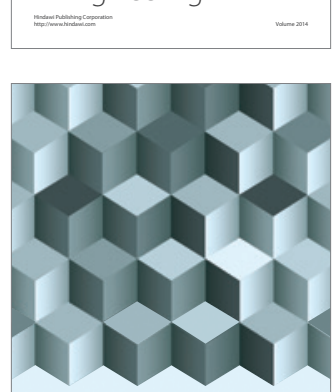

Journal of

Function Spaces
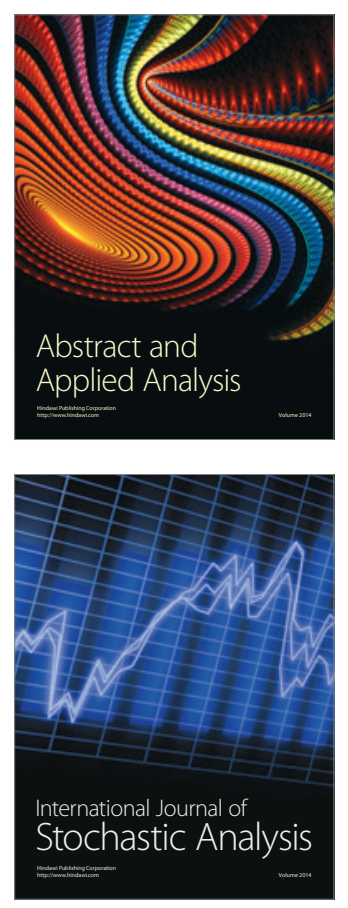

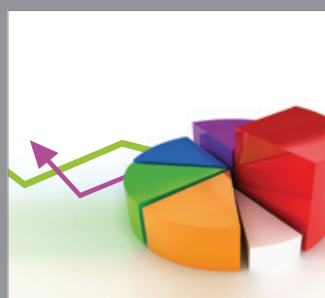

ournal of

Probability and Statistics

Promensencen
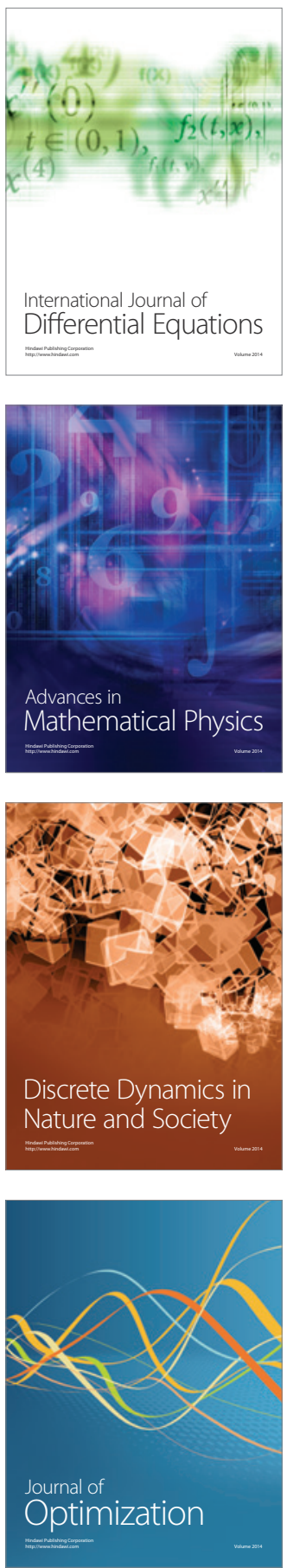